Research Article

\title{
Coupling Coordinated Development Model of Urban-Rural Logistics and Empirical Study
}

\author{
Xianwen Gong \\ School of Economics and Business Administration, Chongqing University of Education, Chongqing 400065, China \\ Correspondence should be addressed to Xianwen Gong; gongxianwen@126.com
}

Received 6 May 2019; Revised 27 July 2019; Accepted 29 August 2019; Published 16 September 2019

Academic Editor: Francesco Zammori

Copyright (c) 2019 Xianwen Gong. This is an open access article distributed under the Creative Commons Attribution License, which permits unrestricted use, distribution, and reproduction in any medium, provided the original work is properly cited.

\begin{abstract}
This paper builds a coupling coordinated development model for urban-rural logistics based on coupling theory and synergy theory, designs an index system for the coordinated development of urban-rural logistics based on supply chain management, and determines the weight of the index system using the entropy method. Supported by official statistics, this paper measures the level and analyzes the changing trend of the coupling coordinated development of urban-rural logistics from 2001 to 2015 in China. The results show that, in the study period, the orderly development level of both urban and rural logistics was improved, and the coordinated development level of urban-rural logistics generally maintained a slow upward trend. However, the interactive coupling level between urban and rural logistics was stagnant, and the orderly development differences were gradually enlarged. This study suggests that setting up urban-rural logistics integrated systems, including material flow, financing flow, information flow, and commerce flow, has become an effective way to break through the division between urban and rural logistics and realize the coordinated development of urban-rural logistics.
\end{abstract}

\section{Introduction}

The growth of the logistics industry, such as warehousing, transportation, and distribution, has strongly promoted the development of cities and countryside and enhanced communication between urban and rural areas [1]. Increasing attention has been paid to the impact of the development of the logistics industry on cities [2]. With the development of rural e-commerce, the importance of rural logistics has been widely recognized [3]. The logistics industry is an important link between urban and rural areas. Coordinated development between urban and rural logistics could help to break the economic and social system division between urban and rural areas, achieve a reasonable allocation of resources between urban and rural areas, give full play to the role of urban and rural logistics support in regional economic integration, and promote the new urbanization process and urban-rural integration development. In recent years, urban logistics and rural logistics have achieved varying degrees of development [4]. However, the imbalance and uncoordinated situation between urban and rural logistics have intensified over time. On the one hand, transportation and logistics clusters are concentrated primarily in metropolitan areas, and urban logistics has a resource advantage and its development speed is accelerated. On the other hand, the development of rural logistics is relatively backward, and thus, the gap between urban and rural logistics is gradually widening [5]. The dual structure between urban and rural logistics in China has distorted the allocation of market resources, which is not conducive to the development of the regional economy. This has not only led to the urban logistics being developed in the self-enclosed, self-circulation environment but also increased the cost of circulation, hindered the development of agricultural product circulation and the rural economy [6], and restricted the development of urban-rural integration and urbanization. Therefore, it is of great theoretical significance and practical value to pay attention to the coordinated development of urban-rural logistics.

In China, with the development of urbanization and the integration of urban and rural areas, the problem of urban and rural logistics has gradually aroused the interest of 
researchers. Academic circles have mainly focused on the characteristics, functions, difficulties, and solutions of urban and rural logistics. For example, Liu believed that urbanrural logistics in China presented a typical dualistic structure feature and that a solution was to build an urban-rural integrated logistics system and realize its coordinated development [6]. Zhang conducted an empirical study on the relationship between urban-rural logistics development and the income gap between urban and rural areas using the panel data of 31 provinces and regions in China for the period 1998-2007. The study found that the development of the logistics industry can promote the narrowing of the income gap between urban and rural areas [7]. Ding further noted that the integrated development of urban-rural logistics played an important role in eliminating the institutional obstacles that restrict the coordinated development of urban and rural areas, overall planning of urban and rural development, optimizing the rural market system, and improving the living standards of rural residents [8]. Song studied the problems and countermeasures in the construction of urban and rural logistics systems. It is believed that the development of urban and rural logistics should be devoted to the transformation of government functions, improvement of the modernization level of rural logistics, and establishment of a government management system that is adapted to the two-way logistics development of urban and rural areas in order to realize the integration of urban-rural trade economy [9]. Taking Chongqing as an example, Qin et al. analyzed the development of urban and rural logistics using the SWOT method and proposed the building of a two-way urban-rural logistics system in Chongqing [10]. Lu established the network optimization model of the distribution center and the purchase center of agricultural products and demonstrated the optimization problem of the chain management distribution network under the integration of urban-rural logistics [11]. From the perspective of public service equalization, using the theory of logistics system engineering, Zhou et al. studied the integrated development of urban and rural logistics under a new situation [12]. Based on the national statistical data of the period 2004-2013, Liang and Zhang empirically analyzed the impact of urban-rural integration, rural logistics, and rural finance on farmers' income using principal component analysis [13]. In summary, the existing achievements have laid the foundation for further research.

This paper differs from the previous research in the following two respects. First, unlike most articles that consider urban logistics and rural logistics separately as two independent issues and neglect the connection between the two, this paper considers urban-rural logistics a unified system. This paper regards urban and rural logistics as a system, establishes a model of urban-rural logistics complex systems using coupling theory and synergy theory, designs an index system based on the concept of supply chain management, and analyzes the mutual coupling degree and coordinated development level of various elements in the urban-rural logistics complex system. Second, most of the articles in this area have mainly focused on theoretical analysis and qualitative research, while studies using empirical analysis and quantitative research are lacking. Based on the statistical data from 2001 to 2015, this paper conducts empirical research on urban-rural logistics using coupling coordinated development models, quantitatively calculating the orderly development level of urban-rural logistics subsystems and coupling the coordinated degree of composite systems, and proposing corresponding countermeasures and suggestions.

This paper is organized as follows. In Section 2, we design an index system for urban-rural logistics. A coordinated development model of urban-rural logistics is proposed in Section 3. Section 4 presents the empirical research, including the data processing, index weight calculation, and coupling coordination analysis of urban-rural logistics. Section 5 discusses the results, and Section 6 concludes the paper.

\section{Index System}

Supply chain management, as the inevitable outcome when logistics is developed in both breadth and depth, the logical extension of logistics, and a more advanced stage of logistics management [14], has become a new management mode to improve operating efficiency. In the new normal development stage of the economic growth rate shift, structural adjustment and optimization, and reform and opening up in China, one important development trend of the logistics industry is the movement toward supply chain management [15]. According to the definition implemented by the national standard in 2001, supply chain management refers to comprehensive planning of business flow, material flow (logistics), information flow, and capital flow in the supply chain by the use of computer network technology, as well as organizing, coordinating, and controlling. The four flows of the supply chain are closely linked. The capital flow, information flow, and business flow are a strong support, basic guarantee, and important premise in the development of logistics. Based on this thinking, the paper could establish the index system of coordinated development between urban and rural logistics considering the above four aspects.

2.1. Urban-Rural Material Flow. Under the long-term economic and social dualistic structure system in China, urban logistics has developed rapidly, but rural logistics has lagged behind. In the process of urbanization, the gap between urban and rural logistics has gradually increased, leading to the dualistic structure between urban and rural logistics. The key to breaking the dualistic structure between urban and rural logistics and realizing the integration of urban and rural commodity circulation is the construction of an urbanrural two-way logistics system, named "industrial products going to the countryside and agricultural products entering the city." Therefore, the urban-rural material flow focuses on two aspects. The first is the logistics activities in which industrial products and consumer goods flow from the city to the countryside through the wholesale market or logistics distribution center. The other is the logistics activities in which agricultural products flow from farmers or 
agricultural managers in the countryside to terminal market consumers in the city. Considering the approaches of other scholars, this study reflects the logistics demand and logistics scale of industrial products using the industrial output value and the total amount of industrial logistics. Similarly, the paper adopts the total output value of agricultural products and the total amount of agricultural products logistics to reflect the demand and scale of agricultural products logistics, respectively. In addition, the mileage of the postal service delivery route reflects the logistics size to a certain extent. Therefore, urban and rural postal service delivery routes could represent the logistics size of the city and countryside to some extent.

2.2. Urban-Rural Capital Flow. Safe and efficient capital flow is a basic guarantee for logistics to operate smoothly, which requires the reasonable allocation of financial resources between urban and rural financial markets, establishes smooth and efficient urban and rural financial channels, and provides more funding for the development of logistics and the logistics systems of urban and rural construction. It is necessary to establish an urban-rural capital operation system when facing the need for logistics, as well as to scientifically and rationally allocate the flow of money for logistics activities through the application and development of a variety of financial products. The indexes commonly used to measure the development of urban and rural finance are financial development size and financial development efficiency. One of the typical indexes used to measure the size of financial development is McKinnon's index, that is, the proportion of M2 accounted for in GDP. The study shows that China's financial structure is bank-oriented, so using the proportion of bank loans to GDP as an index to measure the scale of financial development is reasonable. Based on previous scholars, considering the availability of statistical data, this study adopts the index to measure the urban financial scale using the ratio of the urban loan balance to the industrial output value and measures the rural financial scale using the ratio of the rural loan balance to the agricultural output value. In terms of the efficiency of financial development, most scholars prefer the index of the ratio of loans to deposits. It can reflect not only the efficiency when financial institutions convert savings into loans but also the status of the rural fund outflow to a certain extent [16]. Based on this approach, this paper measures the efficiency of urban financial development using the index of the ratio of the urban loan balance to the urban saving balance and measures the efficiency of rural financial development using the index of the ratio of the rural loan balance to the rural saving balance.

2.3. Urban-Rural Information Flow. Information circulation is one of the most basic functions of logistics activities. As a basic component of logistics activities, information flow is the basis for the formulation, organization, and coordination of logistics activities. With the development of information technology, the scope of logistics service has been expanded, the management of logistics organization has been improved, and logistics capability and logistics efficiency have been enhanced [17]. The wide application of modern information technology, such as computer technology, communication technology, and internet technology, not only profoundly changes work and lifestyle in urban areas but also has a great impact on rural economic and social aspects. In fact, informatization has become an important means to break the bondage of dualistic economic and social systems between urban and rural areas and promote the integration of urban and rural areas. Conversely, the unbalanced development of informatization would result in the emergence and further expansion of the so-called "digital gap" between urban and rural areas. Computers, communication, and the internet have become the symbol and development trend of economic and social information construction, so the two indexes urban fixed telephone users and the computer ownership of urban residents could represent the level of urban informatization, and the rural fixed telephone users and the computer ownership of rural residents could reflect the level of rural informatization.

2.4. Urban-Rural Business Flow. As the starting point of the time value and the premise of the spatial effect of logistics, the business flow, in general, exists in the form of transactions, which are essentially the transfer of commodity ownership. The urban-rural commercial and trade circulation system has the characteristics of two-way interaction and complementary and win-win development, and it is a bridge connecting urban and rural areas in the process of economic and social development [18]. In China, the construction of an urban-rural two-way trade circulation system is of great significance to improve circulation efficiency, reduce circulation costs, expand domestic demand, and promote the development of the national economy. The obstruction of the urban-rural circulation system is closely related to factors such as the serious unequal purchasing power of urban and rural areas, urban and rural production markets, urban and rural commodity market segmentation, and development imbalance between urban and rural circulation markets. In previous studies, the indexes used to measure business flow mainly included the income level of urban and rural residents, the transaction scale of the circulation market, and the number of circulation markets. Based on the processing method in [19], the purchasing power, trade size, and market development degree of urban areas in urban-rural circulation activities could be represented by the income level of urban residents, industrial product trading scale, and number of comprehensive industrial product markets. Similarly, the purchasing power, trade size, and market development degree of rural areas in urban-rural circulation activities could be represented by the income level of rural residents, agricultural product trading scale, and number of comprehensive agricultural product markets. In summary, the index system of the coordinated development of urban-rural logistics could be established as in Table 1.

Overall, the index system in Table 1 embodies the following basic principles. The first principle is scientific. 
TABLE 1: Index system of urban-rural logistics.

\begin{tabular}{|c|c|c|c|c|}
\hline Subsystem & Dimension & Index & Description & Code \\
\hline \multirow{10}{*}{$\begin{array}{l}\text { Urban logistics } \\
\text { subsystem }\end{array}$} & \multirow{4}{*}{ Material flow } & Industrial product logistics demand & Output value of industrial products & UL1 \\
\hline & & Industrial product logistics scale & Total amount of industrial product logistics & UL2 \\
\hline & & Urban logistics size & City postal service delivery route & UL3 \\
\hline & & Urban finance scale & Balance of urban loans/industrial output value & UL4 \\
\hline & Capital flow & Urban financial efficiency & $\begin{array}{c}\text { Balance of urban loans/balance of urban } \\
\text { savings deposits }\end{array}$ & UL5 \\
\hline & \multirow{3}{*}{$\begin{array}{l}\text { Information } \\
\text { flow }\end{array}$} & City fixed telephone users & Original statistical indexes & UL6 \\
\hline & & Urban residents' computer ownership & Original statistical indexes & UL7 \\
\hline & & Income level of urban residents & $\begin{array}{c}\text { Per capita disposable income of urban } \\
\text { residents }\end{array}$ & UL8 \\
\hline & \multirow[t]{2}{*}{ Business flow } & Industrial transaction size & Turnover of industrial product market & UL9 \\
\hline & & Industrial trading environment & $\begin{array}{l}\text { Number of industrial product comprehensive } \\
\text { markets }\end{array}$ & UL10 \\
\hline \multirow{8}{*}{$\begin{array}{l}\text { Rural logistics } \\
\text { subsystem }\end{array}$} & Material flow & $\begin{array}{l}\text { Agricultural product logistics demand } \\
\text { Agricultural product logistics scale } \\
\text { Rural logistics business size }\end{array}$ & $\begin{array}{l}\text { Output value of agricultural products } \\
\text { Total amount of agricultural product logistics } \\
\text { Rural postal service delivery route }\end{array}$ & $\begin{array}{l}\text { RL1 } \\
\text { RL2 } \\
\text { RL3 }\end{array}$ \\
\hline & \multirow{2}{*}{ Capital flow } & Rural financial scale & $\begin{array}{l}\text { Rural loan balance/output value of agricultural } \\
\text { products }\end{array}$ & RL4 \\
\hline & & Rural financial efficiency & $\begin{array}{c}\text { Rural loan balance/rural savings deposits } \\
\text { balance }\end{array}$ & RL5 \\
\hline & \multirow{3}{*}{$\begin{array}{l}\text { Information } \\
\text { flow }\end{array}$} & Rural fixed telephone users & Original statistical indexes & RL6 \\
\hline & & Rural residents' computer ownership & Original statistical indexes & RL7 \\
\hline & & Income level of rural residents & Per capita disposable income of rural residents & RL8 \\
\hline & \multirow{2}{*}{ Business flow } & Scale of agricultural trade & Turnover of agricultural product market & RL9 \\
\hline & & $\begin{array}{l}\text { Agricultural product trading } \\
\text { environment }\end{array}$ & $\begin{array}{l}\text { Number of agricultural product } \\
\text { comprehensive markets }\end{array}$ & RL10 \\
\hline
\end{tabular}

Index systems based on the concept of supply chains can better reflect the scientific connotation of logistics development and conform to the development trend of modern logistics than can other systems. The second principle is systematic. The indicators designed from the four dimensions of the supply chain concept are interdependent and closely related and constitute a system together, which reduces randomness and effectively avoids major omissions and deficiencies. The third principle is independence. Each of the above indicators has its own specific meaning and representativeness. They are independent of each other without overlapping and duplication. The fourth principle is operability, which involves ensuring that statistical data can be obtained and that operability can be increased.

\section{Research Methods}

3.1. Entropy Weight Function. The entropy weight method is an objective weighting method that decides the index weight through the information amount provided by the entropy value of each index. The use of the entropy weight method to weight each index can avoid the interference of human factors in the weight of each evaluation index and make the evaluation result more in line with reality. Generally, entropy refers to disorder or uncertainty. Shannon entropy was introduced by Claude E. Shannon in his 1948 paper, "A Mathematical Theory of Communication." In information theory, entropy is a measure of the disorder degree of a system. The higher the order degree of a system is, the smaller the entropy is and the greater the amount of information contained in the system is. According to the theory, Shannon entropy is defined as $H=-s \sum p_{i} \ln p_{i}$.

For a particular assessment problem, there is a raw data matrix $X$ formed of $m$ years and $n$ indexes; the element $x_{i j}$ in the matrix represents the raw data value of the year $i(i=$ $1,2, \ldots, m)$ to the index $j(j=1,2, \ldots, n)$ :

$$
X=\left[\begin{array}{cccc}
x_{11} & x_{12} & \ldots & x_{1 n} \\
x_{21} & x_{22} & \ldots & x_{2 n} \\
\vdots & \vdots & \vdots & \vdots \\
x_{m 1} & x_{m 2} & \ldots & x_{m n}
\end{array}\right] .
$$

The raw data in matrix $X$ must be standardized to eliminate the effects of different dimensions and magnitude, and then, these data can be used in entropy calculations. Standardization operation should utilize an appropriate calculation method in accordance with the entropy calculation and the nature of the indexes. Commonly used standardization methods, such as $z$-score and equalization, could eliminate the effects of different dimensions and magnitudes. Therefore, the $z$-score method is not suitable for use because the data normalized by this method are distributed between -1 and 1 , and there is a logarithm in the entropy calculations. The equalization method could not guarantee that the value of all processed data is positive, and thus, it is also not suitable for use. Range standardization is a suitable method here, and its formula is as follows: 


$$
\begin{cases}r_{i j}=\frac{x_{i j}-\min \left(x_{i j}\right)}{\max \left(x_{i j}\right)-\min \left(x_{i j}\right)}, & \text { for positive indexes, } \\ r_{i j}=\frac{\max \left(x_{i j}\right)-x_{i j}}{\max \left(x_{i j}\right)-\min \left(x_{i j}\right)}, & \text { for reverse indexes. }\end{cases}
$$

For positive indexes (the larger the superior), the formula above is suitable. For reverse indexes (the smaller the superior), the formula below is suitable. The processing result forms the standardization matrix $R=\left(r_{i j}\right)_{m \times n}$, $0 \leq r_{i j} \leq 1$.

For an index, the greater the difference in the evaluation index values, the larger the amount of information contained in this index, and the greater the effect of this index. According to the concept of entropy, the increase in information means a reduction in entropy, and entropy can be used to measure the size of this information. The feature proportion of year $i$ under index $j$ can be defined as follows:

$$
p_{i j}=\frac{r_{i j}}{\sum_{i=1}^{m} r_{i j}} \text {. }
$$

The Shannon entropy of index $j$ can be defined as follows:

$$
E_{j}=-k \sum_{i=1}^{m} p_{i j} \ln p_{i j}, \quad j=1,2,3, \ldots, n,
$$

where $k=1 / \ln m$, when $p_{i j}=0$ and $p_{i j} \ln p_{i j}=0$. The entropy weight of index $j$ can be defined as follows:

$$
\omega_{j}=\frac{1-E_{j}}{n-\sum_{j=1}^{n} E_{j}}
$$

where $0 \leq \omega_{j} \leq 1, \sum_{j=1}^{n} \omega_{j}=1$, and the characteristics of the entropy weight are as follows.

When the index values of each evaluated object are entirely equal, the entropy value is the maximum and the entropy weight is zero. This means that the index does not provide any useful information for decision-makers; this index can be considered canceled.

When the index values of each evaluated object are quite different, the entropy value is smaller and the entropy weight is large. This means that the index provides decision-makers with useful information, and this index should be focused on.

The larger the entropy value of the index is, the smaller the value of entropy weight is and the less important the index is.

Entropy weight has special significance; it is not the actual importance factor of the given indexes in the process of decision or assessment but rather the relative intensity factor of each index in a competitive sense under the condition that each evaluation index value has been determined after a given set of evaluated objects.

From the information point of view, entropy weight represents the extent of useful information provided by the index in question.
3.2. Order Degree Function. Based on the basic principles of synergetics, coordination refers to harmony between systems or elements of system components in the process of evolution. To achieve the harmony of the system, a number of regulation and control activities imposed on the system are needed, which are called coordination roles. All possible regulation and control activities (coordination roles) and the appropriate procedures and rules are known as coordination mechanisms [20].

Take urban-rural logistics as a composite system that is composed of two subsystems: urban logistics and rural logistics. The complex interactions within the system may have a synergistic effect and form a virtuous circle to promote the orderly development of the composite system. These interactions may also have a negative impact and lead the system in a disordered direction [21]. According to coupling theory and synergy theory, the interaction level between urban and rural logistics subsystems or elements is called the coupling degree, and the harmony level between urban and rural logistics subsystems or components in development processes is called the coordination degree. In the composite system of urban-rural logistics, the slow relaxation variable (order parameter) is the fundamental variable that determines the evolution of complex systems. The key to the evolution of urban-rural logistics complex systems is the synergy between the internal order parameters. The coupling coordination degree is simply the measure of this synergy [22].

Assume that the order parameter in the evolution process of the urban-rural logistics composite system is $u_{i}(i=1,2)$, so that $u_{i j}(j=1,2,3, \ldots, n)$ is any component of the order parameter $u_{i}$ and that the value is $X_{i j}$. The upper and lower limits of the order parameter are $\alpha_{i j}$ and $\beta_{i j}$, respectively, and the contribution that this order parameter promotes the orderly development of the composite system can be expressed as

$$
U\left(u_{i j}\right)= \begin{cases}\frac{X_{i j}-\beta_{i j}}{\alpha_{i j}-\beta_{i j}}, & u_{i j} \text { has positive effect, } \\ \frac{\alpha_{i j}-X_{i j}}{\alpha_{i j}-\beta_{i j}}, & u_{i j} \text { has negative effect, }\end{cases}
$$

where $U\left(u_{i j}\right)$ is the order degree of the order parameter $u_{i j}$ and $U\left(u_{i j}\right) \in[0,1]$. The larger the value is, the greater the contribution of the order parameter is to the system. The total contribution of the order parameter to the system can be achieved by integration, and the formula is as follows:

$$
U\left(u_{i}\right)=\sum_{j=1}^{n} \lambda_{i j} U\left(u_{i j}\right),
$$

where $U\left(u_{i}\right)$ is called the order degree of the subsystem, $U\left(u_{i}\right) \in[0,1], \lambda_{i j}$ is the weight of the order parameter, and $\sum_{j=1}^{n} \lambda_{i j}=1, \lambda_{i j} \geq 0$. The greater the order degree of the subsystem is, the higher the orderly development level of the system is and vice versa [23]. 
3.3. Coupling Coordination Function. Referring to the concept of capacitive coupling and the model of capacity coupling coefficient in physics, the interaction coupling model of multiple systems (or elements) is generalized [24]. The formula $C_{n}=\left\{\left(u_{1} \cdot u_{2} \cdot \ldots \cdot u_{m}\right) /\left[\prod\left(u_{i}+u_{j}\right)\right]\right\}^{1 / n}$ could represent the coupling degree under multisystem interaction conditions. Therefore, the coupling function of the urbanrural logistics composite system can be expressed as

$$
C=\frac{\left[U\left(u_{1}\right) \cdot U\left(u_{2}\right)\right]^{1 / 2}}{U\left(u_{1}\right)+U\left(u_{2}\right)},
$$

where $C$ is the coupling degree of the urban-rural logistics composite system, $U\left(u_{1}\right)$ is the order degree of the urban logistics subsystem, and $U\left(u_{2}\right)$ is the order degree of the rural logistics subsystem.

Obviously, $C \in[0,1]$, and the greater the value of the coupling degree is, the higher the coupling strength is. The coupling degree can better reflect the coupling strength between urban and rural logistics but cannot reflect the coordination level. Therefore, it is necessary to establish the following coupling coordination function to analyze the coordination degree of interaction coupling between urban and rural logistics:

$$
\left\{\begin{array}{l}
D=(C \cdot T)^{1 / 2} \\
T=a \cdot U\left(u_{1}\right)+b \cdot U\left(u_{2}\right),
\end{array}\right.
$$

where $D$ is the coupling coordination degree, $T$ is the coordination indicator of urban-rural logistics, reflecting the effect and contribution of the comprehensive evaluation index of the two subsystems to their coordination degree, and $a$ and $b$ are the undetermined coefficients. In the process of coupling coordination development, urban logistics and rural logistics are supplementary and indispensable to each other and of equal importance. Referring to previous studies and interviews in related fields $[25,26]$, the coefficient values of this study are $a=0.5$ and $b=0.5$.

\section{Empirical Study}

4.1. Data Statistics and Index Weight Calculation. This paper mainly studies the coupling coordinated degree between urban and rural logistics in China and analyzes their coupling coordination development trend from 2001 to 2015. The original data come from the China Statistical Yearbook, China Logistics Yearbook, China Finance Yearbook, China Rural Statistical Yearbook, the National Economic and Social Development Statistical Bulletin released by National Bureau of Statistics, the China Logistics Development Report released by the Federation of Logistics and Purchasing, and the professional statistical database of the Ministry of Industry and Information Technology.

Referring to the relevant literatures [27], the upper and lower limits of order parameters are calculated by adding or reducing $1 \%$ of their maximum and minimum values, respectively, on the basis of historical actual values. The statistical matrix (1) formed by the original data above could be standardized using formula (2). According to formulas
(3)-(5), the entropy value and entropy weight of each order parameter is calculated and given in Table 2 .

4.2. Order Development Analysis. Using formulas (6) and (7), the paper calculates the order degree of urban and rural logistics subsystems. To further compare the differences between urban and rural logistics, the order degree of any subsystem of urban-rural logistics at the initial moment can be defined as $U\left(u_{i}^{0}\right)$, and the order degree of a certain time can be defined as $U\left(u_{i}^{t}\right)$, then $U\left(u_{i}^{t}\right)-U\left(u_{i}^{0}\right)$ reflects the evolution trend of the orderly development of any subsystem. Thus, the difference degree of orderly development between the two can be defined as $K=\left[U\left(u_{1}^{t}\right)-U\left(u_{1}^{0}\right)\right]-\left[U\left(u_{2}^{t}\right)-U\left(u_{2}^{0}\right)\right]$, which reflects the difference in orderly development and its trend between urban and rural logistics. The larger the absolute value of the difference degree is, the greater the differences between the two are. When the value of $K$ is greater than zero, urban logistics are in a leading position, rural logistics lag behind, and vice versa. The calculated results are provided in Table 3.

First, it can be seen from Figure 1 that the order degree curve of the urban and rural logistics systems continued to rise alternately from 2001 to 2015, showing that the orderly development level of both urban and rural logistics has been continuously improved in the past fifteen years. The order degree of urban logistics greatly increased from 0.0784 in 2001 to 0.8942 in 2015 . In addition, the order degree of rural logistics slightly increased from 0.1483 in 2001 to 0.8098 in 2015.

Second, from 2001 to 2015, the difference degree curve of the orderly development of urban and rural logistics showed an upward trend, and the difference degree increased from 0.0358 in 2002 to 0.1543 in 2015, indicating that the orderly development gap between urban and rural logistics was widening. The orderly development level of urban logistics was ahead of that of rural logistics and made a greater contribution to the coordination development of urbanrural logistics. Since the orderly development of rural logistics lagged behind that of urban logistics, it contributed less to the coordination development and became the constraint factor (Figure 1).

4.3. Coupling Coordination Analysis. Using formulas (8) and (9), the paper calculates the coupling coordinated degree of urban-rural logistics, and the results are shown in Table 4.

From the perspective of supply chain integration, the coupling coordinated level between urban and rural logistics in China was rising slowly in fluctuation in the period 2001-2015, but there was hardly any change in the coupling level between urban and rural areas (Figure 2). This means that both urban and rural logistics in China have developed to a certain extent, and the level of coordination has improved after years of effort. However, the separation situation between urban and rural logistics has not been substantially changed, the feature of dual systems remains remarkable, and the coordinated development between urban and rural logistics has room for improvement. 
TABLE 2: Entropy value and entropy weight of order parameter.

\begin{tabular}{lcccccccccc}
\hline Index & UL1 & UL2 & UL3 & UL4 & UL5 & UL6 & UL7 & UL8 & UL9 & UL10 \\
\hline Entropy value & 0.8773 & 0.8570 & 0.9042 & 0.8958 & 0.9043 & 0.9485 & 0.9245 & 0.8724 & 0.8172 & 0.9294 \\
Entropy weight & 0.1147 & 0.1337 & 0.0896 & 0.0974 & 0.0895 & 0.0481 & 0.0706 & 0.1193 & 0.1709 & 0.0660 \\
Index & RL1 & RL2 & RL3 & RL4 & RL5 & RL6 & RL7 & RL8 & RL9 & RL10 \\
Entropy value & 0.8445 & 0.8472 & 0.9038 & 0.8741 & 0.8374 & 0.9419 & 0.8123 & 0.8427 & 0.8579 & 0.9512 \\
Entropy weight & 0.1208 & 0.1187 & 0.0747 & 0.0978 & 0.1264 & 0.0452 & 0.1458 & 0.1223 & 0.1104 & 0.0379 \\
\hline
\end{tabular}

Table 3: Order degree and differences between urban and rural logistics.

\begin{tabular}{cccc}
\hline Year & $U\left(u_{1}\right)$ & $U\left(u_{2}\right)$ & $K$ \\
\hline 2001 & 0.0784 & 0.1483 & - \\
2002 & 0.1529 & 0.1870 & 0.0358 \\
2003 & 0.1966 & 0.2319 & 0.0346 \\
2004 & 0.2308 & 0.2426 & 0.0581 \\
2005 & 0.1877 & 0.1969 & 0.0607 \\
2006 & 0.2400 & 0.2347 & 0.0752 \\
2007 & 0.3299 & 0.3013 & 0.0985 \\
2008 & 0.3107 & 0.2690 & 0.1116 \\
2009 & 0.4093 & 0.3299 & 0.1493 \\
2010 & 0.5160 & 0.4002 & 0.1857 \\
2011 & 0.5687 & 0.4981 & 0.1405 \\
2012 & 0.6634 & 0.7131 & 0.0202 \\
2013 & 0.7356 & 0.6551 & 0.1504 \\
2014 & 0.8450 & 0.7565 & 0.1584 \\
2015 & 0.8942 & 0.8098 & 0.1543 \\
\hline
\end{tabular}

On the one hand, in the process of supply chain integration, urban logistics and rural logistics in China have maintained a relatively stable and orderly development trend. At the same time, the urban-rural financial services industry, information industry, and commercial circulation industry further integrated with the urban-rural logistics industry, providing a guarantee and support for the coordinated development of urban-rural logistics.

First, the state has paid great attention to urban-rural integration and urban-rural logistics development in recent years. Regarding construction goals, including the urbanrural logistics network of "urban distribution, intercity distribution, and rural distribution" and the modern urbanrural logistics system of "smooth and efficient, coordinated, and supporting," the state has promulgated a series of supporting policies, regulations, and measures. The development environment of urban-rural logistics has been continuously improved, and policy effects are gradually emerging. In 2015, the total amount of social logistics reached 219.2 trillion $\mathrm{CNY}$, an increase of $5.8 \%$ over the previous year, the total logistics volume of industrial products was 204 trillion CNY, an increase of $6.1 \%$ over the previous year, and the total logistics volume of agricultural products was 3 trillion CNY, an increase of $3.9 \%$ over the previous year.

Second, the urban-rural finance scale continues to expand, the efficiency of financial services has been further improved, and the support for urban-rural logistics has been increasing. In 2014, the urban savings deposits balance reached 36.9 trillion $\mathrm{CNY}$, an increase of $6.6 \%$ over the previous year, and the rural savings deposits balance reached
11.6 trillion $\mathrm{CNY}$, an increase of $16.6 \%$ over the previous year. The urban loan balance over the same period continued to increase, and the loans of financial institutions for warehousing, transportation, and logistics industry reached 8.3 trillion CNY. The loans related to agriculture reached 23.6 trillion CNY, accounting for $28 \%$ of loans and an increase of $13 \%$ over the previous year.

Third, facing the needs of urban-rural integration development, the information industry conscientiously implemented the state's policy measures of "steadying growth, promoting reform, adjusting structure, improving livelihood, and preventing risk," further promoted the "broadband China" strategy, improved 4G network coverage and broadband infrastructure, accelerated the pace of mobile communication facilities, and constantly improved the broadband infrastructure. The information level of both urban and rural areas has been improved, providing a guarantee for the coordinated development of urban-rural logistics. In 2014, the number of internet broadband access ports reached 470 million, a net increase of 73.2 million and an increase of $18.3 \%$ over the previous year.

Fourth, the state has adopted many measures in the circulation of commerce and trade to promote the integration of urban-rural business. The project to encourage retailers to open stores in more townships and villages and engineering to support 100 large wholesale markets for farm products and 100 large rural retail distributors both progressed smoothly. Urban-rural commodity circulation has entered into a new normal period of rational development, in which the pursuit goal transformed from speed and scale to quality and efficiency. The market scale of urban and rural areas continued to expand, and the rural consumer goods market was becoming increasingly active. Since 2012, the growth rate of consumption in rural areas has been higher than that in urban areas. For example, the increase in the total retail sales of social consumer goods was $14.3 \%$ and $14.5 \%$ in $2012,12.9 \%$ and $14.6 \%$ in 2013 , and $11.8 \%$ and $13.0 \%$ in 2014 in urban and rural areas, respectively.

On the other hand, the coupling strength between urban and rural logistics changed very little, and the coupling level was stagnant, which fully reflected the separation situation of urban-rural logistics. At the same time, the "twin effect" of the dual economic structure in China has existed in finance, information, and circulation fields for a long time, resulting in the division between urban and rural areas from each other in finance, information, and trade circulation fields, weakening the support of capital flow, information flow, and business flow for urban-rural logistics and restricting the coordinated development of urban-rural logistics. 


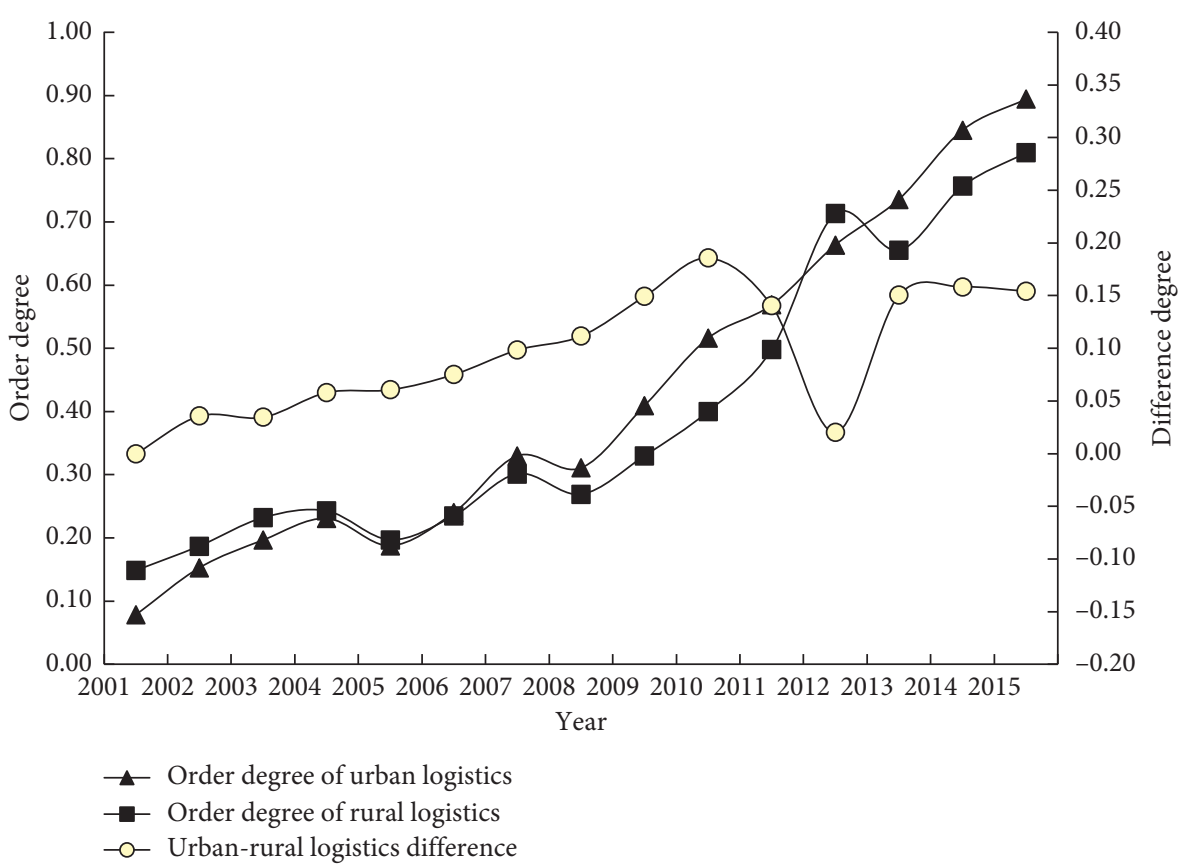

FiguRE 1: Order degree and difference of urban-rural logistics.

TABLE 4: Coupling coordinated degree of urban-rural logistics.

\begin{tabular}{ccc}
\hline Year & $C$ & $D$ \\
\hline 2001 & 0.4756 & 0.2322 \\
2002 & 0.4975 & 0.2908 \\
2003 & 0.4983 & 0.3267 \\
2004 & 0.4998 & 0.3440 \\
2005 & 0.4999 & 0.3100 \\
2006 & 0.5000 & 0.3445 \\
2007 & 0.4995 & 0.3970 \\
2008 & 0.4987 & 0.3802 \\
2009 & 0.4971 & 0.4286 \\
2010 & 0.4960 & 0.4767 \\
2011 & 0.4989 & 0.5159 \\
2012 & 0.4997 & 0.5864 \\
2013 & 0.4992 & 0.5891 \\
2014 & 0.4992 & 0.6323 \\
2015 & 0.4994 & 0.6523 \\
\hline
\end{tabular}

First, although the process of urbanization promoted the development of the logistics industry in urban and rural areas, under the long-term existence of dual systems in urban and rural areas, it is difficult to form synergistic effects between urban and rural logistics [19], and the coordinated development level is not high. The rational flow of logistics factors such as technology, capital, and talent is limited in urban and rural areas and concentrated in urban areas. With the continuous improvement of the urbanization level, the logistics infrastructure of the urban areas, such as the transportation network and information system, has been improved day by day, while the infrastructure of rural logistics is still relatively backward. At the same time, the industry concentration degree of rural logistics under the rural farmers system is still low, so it is difficult to form a scale effect. Moreover, these phenomena, such as the high cost of logistics, self-employed logistics management mode, low service level, poor ability to resist risks, development retardation of rural economic cooperation organization, and lack of competitive business entities, are more common than others. Under the influence of a variety of factors, urban logistics has the advantages of development, the development of rural logistics lags behind, and the gap between urban and rural logistics development is widening. The coordinated development of urban-rural logistics is still facing severe challenges.

Second, since the reform and opening up, the government has paid more attention to the innovation and development of urban finance for a long time but has ignored the importance of rural financial services. The state lacks an effective compensation policy for rural financial services, and the state-owned banks substantially reduce the financial service outlets in rural areas. Large amounts of rural funds absorbed through postal savings institutions are mainly used for urban construction. Under the constraints of the financial system, a farmer's land (the largest asset) could not be mortgaged, leading to the rural mortgage loan business being insufficient and a rural fund flowing to the city in large quantities [28], while the mechanism of returning urban capital to rural areas is not perfect. In the urban-rural dual financial structure, the "financing difficulty" problem of urban-rural logistics, especially rural logistics, has not changed significantly. Financial support for the coordinated development of urban-rural logistics is limited.

Third, the main problem of urban-rural informatization is that construction in vast rural areas has lagged behind that in urban areas for a long time. Although the country has adopted the "village to village" project, strengthened the construction of the rural information infrastructure, improved the coverage rate of the rural CATV network, 


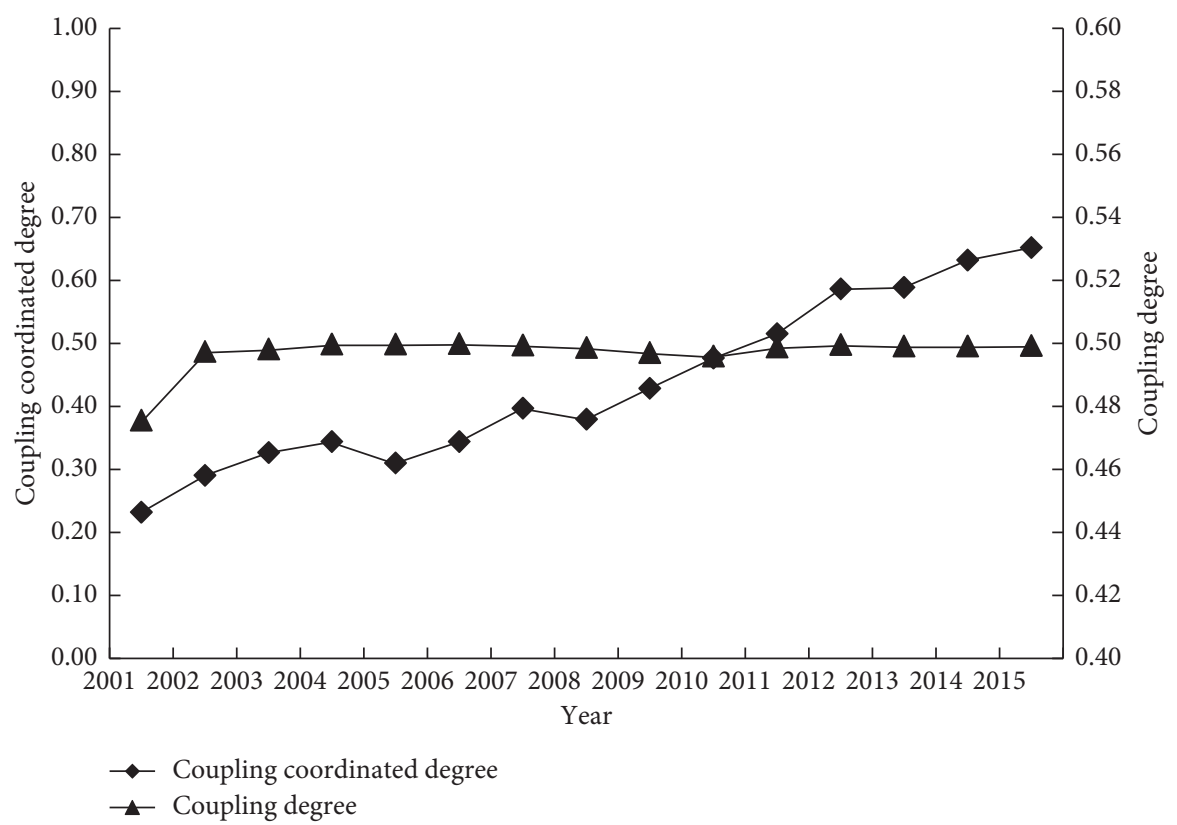

Figure 2: Coupling coordination and evolution trend of urban-rural logistics.

telephone network, and internet, and effectively raised the level of informatization in rural areas, the informatization development level is uneven, and there still exists a large gap between urban and rural areas. Taking the broadband users of urban and rural areas in 2015 as an example, urban broadband users increased by 10.9 million, which is 5.5 times the net increase in rural broadband users. In addition, factors such as a lack of information, information timeliness, and information pertinence further restrict the urban-rural information integration process.

Fourth, from the perspective of commercial circulation, the dual economic structure has formed a dual circulation system in urban and rural areas, which is not conducive to the coordinated development of urban-rural logistics, such as commodity market segmentation, large gap in the commodity market transaction scale and the degree of specialization, element market segmentation, imbalance of labor market and capital market development, unequal trading subject, and the ability differences between urban and rural market transactions. Because of the segmentation of the circulation market between urban and rural areas, factor and commodity flows are blocked, and the purchasing power differences have become large [18]. Taking urbanrural income levels as an example, for a long time, the per capita disposable income of urban residents was approximately 3 times that of rural residents, and the purchasing power between urban and rural areas was significantly different (Table 5). From the circulation process of urbanrural commodities, especially agricultural products, too many circulation links caused by the separation of urbanrural commercial circulation systems may be an important reason for the low efficiency and high cost of urban-rural logistics. In recent years, under the impetus of the project to encourage retailers to open stores in more townships and villages and engineering to support 100 large wholesale markets for farm products and 100 large rural retail distributors in China, commercial circulation markets in both urban and rural areas have achieved varying degrees of development, but the dual segmentation features between urban and rural circulation markets have been difficult to fundamentally change in a short time.

\section{Results and Discussion}

The results show that, in 2001-2015, China's urban-rural logistics development level was improved, the coordinated development level showed a slow upward trend, but the interactive coupling level between urban and rural logistics was stagnant, and the orderly development difference was gradually widening. It is urgent to explore the coordinated development solutions of urban-rural logistics from the four aspects of material flow, capital flow, information flow, and business flow.

\subsection{Building an Urban-Rural Two-Way Flowing Modern} Logistics System, Promoting the Coordinated Development of Urban-Rural Material Circulation. The key to the coordinated development of urban-rural logistics is to establish a modern logistics system of two-way flow between urban and rural areas. Therefore, on the one hand, it is necessary to cultivate more logistics enterprises in the city that can serve the countryside and serve the "industrial goods going to the countryside," relying on the project to encourage retailers to open stores in more townships and villages and the engineering to support 100 large wholesale markets for farm products and 100 large rural retail distributors, support enterprises of agricultural production, industrial production, and daily consumer goods production in urban areas to carry out logistics services in rural areas through policy, incentive, and other means. At the same time, in the current trend of the supply chain 
TABle 5: Per capita disposable income of urban-rural residents (CNY).

\begin{tabular}{|c|c|c|c|c|c|c|c|c|}
\hline Year & 2001 & 2002 & 2003 & 2004 & 2005 & 2006 & 2007 & 2008 \\
\hline Urban residents & 6859.6 & 7702.8 & 8472.2 & 9421.6 & 10493.0 & 11759.5 & 13785.8 & 15780.8 \\
\hline Rural residents & 2366.4 & 2475.6 & 2622.2 & 2936.4 & 3254.9 & 3587.0 & 4140.4 & 4760.6 \\
\hline Year & 2009 & 2010 & 2011 & 2012 & 2013 & 2014 & 2015 & - \\
\hline Urban residents & 17174.7 & 19109.4 & 21809.8 & 24564.7 & 26955.1 & 29381.0 & 31790.3 & - \\
\hline Rural residents & 5153.2 & 5919.0 & 6977.3 & 7916.6 & 8895.9 & 9892.0 & 10772.0 & - \\
\hline
\end{tabular}

business developing to rural areas, urban logistics enterprises should extend the logistics service network from the city to the key villages and towns in rural areas, establishing a distribution network of urban-rural integration [29].

On the other hand, taking the reform of a small peasantbased management system as an important task of rural urbanization construction in China, such as a household contract administration system, the government should vigorously develop rural cooperative economic organizations in rural areas and cultivate a new type of rural logistics subject that could be useful for "agricultural products entering the city" in the countryside. Specifically, the government should be committed to reconstructing the traditional trade circulation organization in rural areas, support a trade system and the postal system to set up special rural logistics companies for rural development, encourage township enterprises, village enterprises, farmers' cooperative enterprises, and rural individual enterprises to enter the logistics market, carry out logistics business, support the wholesalers, and middlemen and retailers of agricultural and sideline products wholesale market to transit to logistics companies, making it an effective business entity to meet the needs of rural logistics development [6]. Simultaneously, we should focus on balancing urban and rural logistics resources and development plans to strengthen the radiation effect of urban logistics on rural logistics.

\subsection{Establishing an Efficient and Safe Urban-Rural Financial} System, Providing Financial Support for the Coordinated Development of Urban-Rural Logistics. On the one hand, rural logistics is a restrictive link of unbalanced urbanrural logistics, taking China's urbanization as an opportunity, and different places should reasonably extend the application fields of rural policy credit funds to a certain scope, expanding the financial support effect of agricultural banks and agricultural development banks on rural logistics, for example, increasing the large-amount and long-term loans to support the development of rural logistics in the loan business of rural commercial banks in China, setting up the payback mechanism of the postal savings funds to rural areas, encouraging insurance institutions to set up corresponding insurance categories to underwrite the storage, transportation, loading and unloading, and other aspects of rural logistics, increasing investment in rural logistics, and taking it as a means of urban areas nurturing rural areas in the process of urbanization.
On the other hand, the practice in recent years has shown that supply chain finance, as a safe and efficient financial mode, could not only improve the efficiency of urban-rural logistics finance but also reduce the risk of capital flow. Therefore, in practice, introducing supply chain management into urban-rural logistics finance is helpful for promoting the "four-flow" integration of material flow, capital flow, information flow, and business flow between urban and rural areas by the internet, big data, cloud computing, and other means. The financial institutions, logistics enterprises, EC enterprises, and data companies of urban and rural areas work together to provide diversified supply chain financial support for the coordinated development of urban-rural logistics, and conduct financial management and integrated financial services for suppliers, producers, and distributors in urban and rural industrial, consumer goods and agricultural products circulation.

\subsection{Promoting the Integration of Urban-Rural Information} Circulation, Providing an Information Guarantee for the Coordinated Development of Urban-Rural Logistics. On the one hand, we should give priority to supporting the construction of rural informatization and further improve the coverage level of the rural "three networks," strengthen the construction of the rural e-commerce information platform, and promote the extension of the e-commerce information network to three or four cities and rural areas, reduce the separation of the urban-rural dual system by the use of information technology, establish a unified urban-rural information network household registration system, and promote the reasonable flow of population resources between urban and rural areas. It is imperative to train information professionals facing the needs for agriculture and rural informatization construction, constantly improve farmer enthusiasm in learning information technology, strengthen cultural information exchange between urban and rural areas, constantly improve farmers' capabilities for information technology, and keep information exchange and information transmission smooth between urban and rural areas.

On the other hand, we should actively explore new models of supply chain information integration in urban and rural areas. For example, Henan Zhongpin established an urban-rural agricultural product supply chain integrated service system with some of the functions of an "information platform + supply chain alliance" through internet technology, built a distribution platform in more than 150 key consumer cities, and provided an "O2O" one-stop service for the trade of agricultural products through the integration of 
resources under the internet platform. Based on the integration of logistics, capital flow, information flow, and business flow, the ZTE supply chain information platform could share information with upstream and downstream enterprises in the supply chain, promote the cooperation of suppliers, manufacturers, and distributors between urban and rural areas, and achieve 360 degrees of transparent visibility in the supply chain.

5.4. Exploring Various Forms of the Urban-Rural Trade Circulation Mode, Creating a Business Environment for the Coordinated Development of Urban-Rural Logistics. On the one hand, the integration of suppliers, manufacturers, distributors, retailers, and end-users of urban and rural areas based on supply chains is helpful for forming a network of two-way trade and circulation systems that combines urban and rural areas and for realizing the unity of the logistics, supply chain, service chain, and value chain of urban and rural areas. The agricultural products business circulation mode of "farmers + cooperative organizations + processing enterprises + electricity supplier/retail terminal + consumer," which is formed through exploration, for example, could integrate the "seed, raise, produce, and sell" links in the upstream and downstream of the agricultural product supply chain, providing integrated services for the commercial circulation of agricultural products.

On the other hand, we should break the segmentation of urban-rural dual markets, establish a unified market system in urban and rural areas, and promote the rational flow of production factors between urban and rural areas. Continuously optimizing the unnecessary links in the urbanrural circulation system effectively reduces the logistics costs of "industrial products to the countryside and agricultural products into the city" and improves the efficiency of circulation. A unified plan for the layout of urban-rural commercial networks and strengthening of the construction of commercial networks in rural areas are needed. For the rural market system, we should actively cultivate diversified business circulation subjects, such as agricultural commodity circulation focusing on large agricultural enterprises in rural areas, rural commodity circulation focusing on supermarket chains, and agricultural products circulation focusing on agricultural cooperatives.

\section{Conclusions}

This paper takes urban-rural logistics as the research object, establishes a coordinated development index system based on supply chain management, determines the index weight using the entropy method, builds a coordinated development model using coupling theory and synergy theory, and empirically researches coordinated development from 2001 to 2015 in China. Finally, the paper discusses the results and proposes some suggestions.

Our research contributes to the extant literature in three ways: (1) The designing of an urban-rural logistics index system based on supply chain management can comprehensively reflect the profound connotation and internal logical relationship of urban-rural logistics development and ensure the scientificity, systematicness, independence, and operability of the index system. Using the entropy method to determine the weight of the indicators can be helpful in reducing the interference of subjective factors and improving the objectivity of the study. (2) The establishment of the coupling coordinated development model using the methods of coupling theory and synergy theory can not only better describe the degree of interaction coupling between urban and rural logistics but also effectively reflect the level of coordinated development of urban and rural logistics. (3) The empirical research on the basis of China's statistical data in the past 15 years illustrates the applicability of the model and the feasibility of the research methods. Analyses on the coupling coordinated development level and evolution trend of subsystems and composite systems are helpful to further identify the deep-seated problems in the coordinated development of urban and rural logistics in China and provide a reference for relevant policy formulations.

From the perspective of the supply chain, the coordinated development of urban-rural logistics is a systematic engineering strategy that includes material flow, capital flow, information flow, and business flow. The interaction mechanism among various elements in subsystems and complex systems of urban-rural logistics presents nonlinear characteristics. The urban-rural logistics system is a complex system that is far from the equilibrium state. Using coupling theory and synergy theory to establish a coupling coordination model and study the coordinated development of urban-rural logistics can deeply reflect these characteristics of the system, which has high effectiveness and adaptability. Therefore, based on the research methods of coupling theory and synergy theory, further analysis of the openness, dynamics, and hierarchy of urban-rural logistics systems will be a valuable research direction in the future.

\section{Data Availability}

The data used to support the findings of this study are available from the corresponding author upon request.

\section{Conflicts of Interest}

The author declares that there are no conflicts of interest.

\section{Acknowledgments}

This work was supported by the Humanities and Social Sciences Research Project of Ministry of Education (Grant No. 19YJA790015), System Innovation Project of Chongqing Science and Technology Bureau (Grant No. cstc2019jsyjzzysbA0017), Chongqing Social Science Planning Project (Grant No. 2017YBJJ042), Humanities and Social Sciences Project of Chongqing Education Commission (Grant No. 18SKGH160), Chongqing Educational Science Planning Project (Grant No. 2018-GX-116), Chongqing Education Reform Key Project (Grant No. 182033), Research Project of Chongqing Education Comprehensive Reform (Grant No. 19JGY42), and Key Scientific Research Project of Chongqing 
University of Education (Grant No. KY201707A), and the author would like to express heartfelt thanks for the support. The author would also like to thank Raghda Radwan and Francesco Zammori for providing constructive comments on the manuscript of this paper.

\section{References}

[1] M. Hesse, "The changing structure of merchandise management and logistics and its effects on urban development," Geographische Zeitschrif, vol. 87, no. 3-4, pp. 223-237, 1999.

[2] K. Aljohani and R. G. Thompson, "Impacts of logistics sprawl on the urban environment and logistics: taxonomy and review of literature," Journal of Transport Geography, vol. 57, pp. 255-263, 2016.

[3] Y. Zhang, Y. Y. Zhang, Y. F. Li, S. Liu, and J. A. Yang, "A study of rural logistics center location based on intuitionistic fuzzy TOPSIS," Mathematical Problems in Engineering, vol. 2017, Article ID 2323057, 7 pages, 2017.

[4] X. Guo, J. Shi, D. Ren, J. Ren, and Q. Liu, "Correlations between air pollutant emission, logistic services, GDP, and urban population growth from vector autoregressive modeling: a case study of Beijing," Natural Hazards, vol. 87, no. 2, pp. 885-897, 2017.

[5] I. Kumar, A. Zhalnin, A. Kim, and L. J. Beaulieu, "Transportation and logistics cluster competitive advantages in the U.S. regions: a cross-sectional and spatio-temporal analysis," Research in Transportation Economics, vol. 61, pp. 25-36, 2017.

[6] B. Liu, "The city-country duality conformation and its countermeasure of Chinese logistics industry development," Inquiry into Economic Issues, vol. 4, pp. 47-49, 2008.

[7] J. S. Zhang, "Logistics development and income difference between urban and rural areas. an empirical analysis based on provincial panel data," Economics and Management, vol. 24, no. 4, pp. 31-35, 2010.

[8] J. F. Ding, "Economic integration of urban and rural areas and development of logistics industry," China Circulation Economy, vol. 25, no. 8, pp. 8-10, 2011.

[9] Y. Song, "Problems and countermeasures in the construction of logistics system for two-way flow of urban and rural areas," Economic Review, vol. 3, pp. 32-35, 2011.

[10] X. H. Qin, G. X. Wei, and J. Zhou, "Bidirectional logistic system of urban and rural balancing: case study of chongqing," Science and Technology Management Research, vol. 31, no. 13, pp. 114-117, 2011.

[11] M. L. Lu, "Study on the optimizing the distribution network in chain operation based on urban-rural logistics integration," Mathematics in Practice and Theory, vol. 42, no. 22, pp. 71-78, 2012.

[12] L. Y. Zhou, W. D. Gu, and J. Zhou, "Integrated development of urban and rural logistics from the perspective of public services equalization," Modern Management Science, vol. 11, pp. 9-11, 2012.

[13] W. Liang and W. Zhang, "The impact of urban-rural integration, rural logistics and rural finance on the income of farmers," Journal of Beijing Jiaotong University, vol. 1, pp. 98-105, 2016.

[14] L. D. Zhao and H. Y. Wang, Supply Chain and Logistics Management, pp. 6-8, Science Press, Beijing, China, 2011.

[15] L. M. He, "Logistics and supply chain development trend and policy expectation of China under the new normal," China Circulation Economy, vol. 8, pp. 4-8, 2014.
[16] L. L. Wei and J. Ma, "The impact of unbalanced development of finance in double hysteresis regions upon the urban-rural income gap," Journal of Lanzhou University, vol. 1, pp. 117125, 2014.

[17] D. M. Xu, C. L. Xiu, and X. Y. Wang, "The information technology and urban-rural integration and corresponding countermeasures," Economic Geography, vol. 24, no. 2, pp. 221-225, 2004.

[18] B. P. Ren, "The necessity and strategy of establishing urbanrural-two-way-flow commercial circulation system," Journal of Business Economics, vol. 10, pp. 5-11, 2011.

[19] B. P. Ren and J. Wei, "Measurement and evaluation on degree of the urban-rural commercial and trade integration," Statistics \&Information Forum, vol. 26, no. 9, pp. 28-34, 2011.

[20] T. W. Malone and K. Crowston, "The interdisciplinary study of coordination," ACM Computing Surveys, vol. 26, no. 1, pp. 87-119, 1994.

[21] H. Bai and W. X. Han, "General theories about complex systems and their coordination," Operations Research and Management Science, vol. 9, no. 3, pp. 1-7, 2000.

[22] Q. S. Meng and W. X. Han, "Study of the coordinating measurement model with respect to composite system," Journal of Tianjin University, vol. 33, no. 4, pp. 444-446, 2000.

[23] Y. X. Wang, "Empirical study of the coupling coordination relationship of urbanization and ecological environment in Nanchang and Jiujiang urban belts," Journal of Interdisciplinary Mathematics, vol. 17, no. 5-6, pp. 511-526, 2014.

[24] V. Illingworth, The Penguin Dictionary of Physics, Foreign Language Press, Beijing, China, 1996.

[25] P. D. Zhang, "Analysis of coupling coordination between regional manufacturing and producer services based on empirical study of 29 provincial regions in China," Development Research, vol. 2, pp. 46-49, 2010.

[26] L. Li and J. Liu, "Researching coordinate development of hightech industry and new-type industrialization in Xinjiang based on coupling degree model," Science \& Technology Progress and Policy, vol. 4, pp. 44-49, 2013.

[27] Y. Zhang and Q. Chen, "Research on coordinating degree of regional logistics industry and economic development in China: based on compound system model and panel data of 30 provinces," Soft Science, vol. 24, no. 12, pp. 70-74, 2010.

[28] H. L. Zhang and C. Y. Zheng, "Inquiry into the income gap of residents and the integration of urban and rural financial services," Financial Theory and Practice, vol. 9, no. 12, pp. 75-78, 2011.

[29] Rural Modern Logistics Research Center Research Group, D. C He, Y. X. Cha et al., "China Rural Logistics Development Report (2013)," vol. 9, pp. 8-30, China Cooperative Economy, China, 2013. 


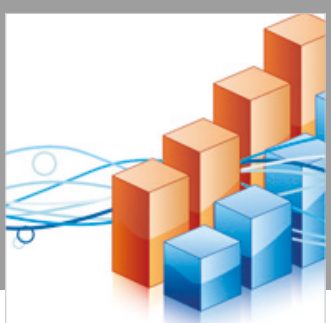

Advances in

Operations Research

\section{-n-m}
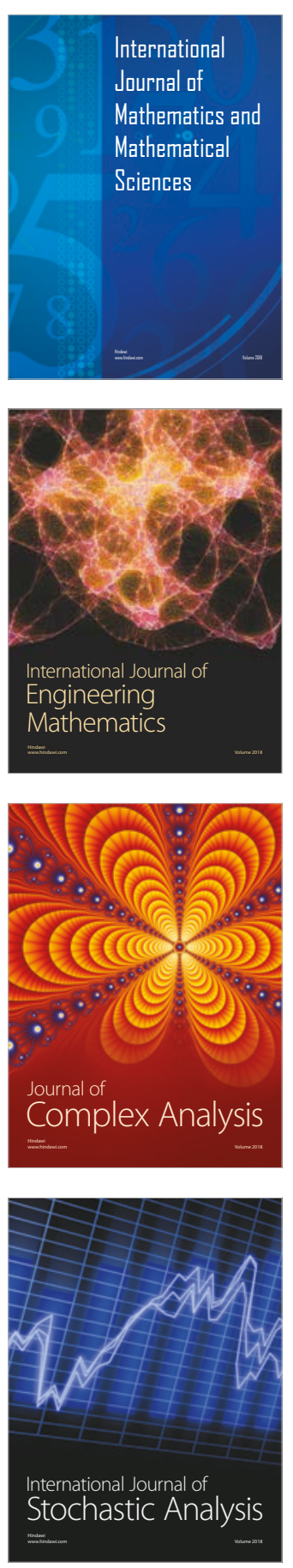
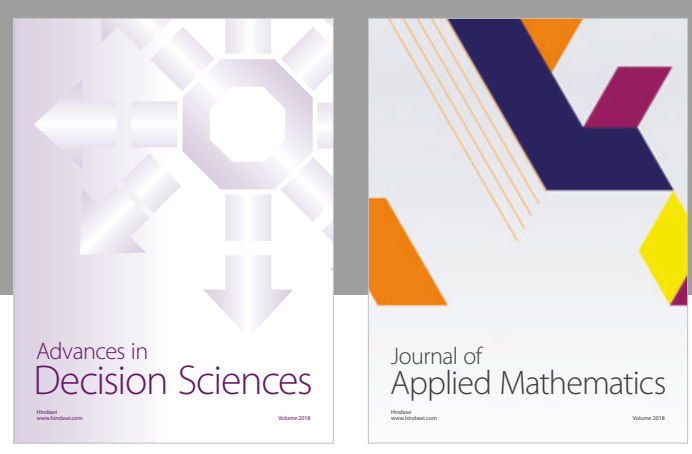

Journal of

Applied Mathematics
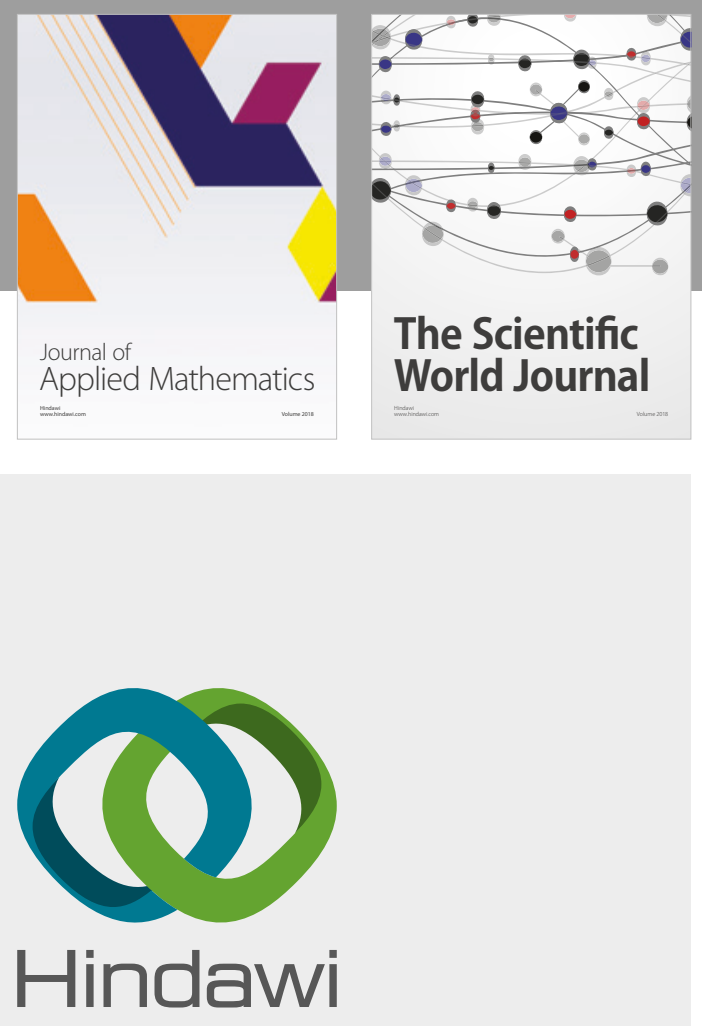

Submit your manuscripts at

www.hindawi.com

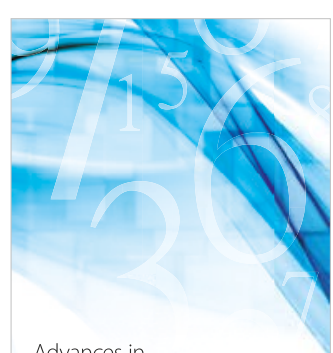

Advances in
Numerical Analysis
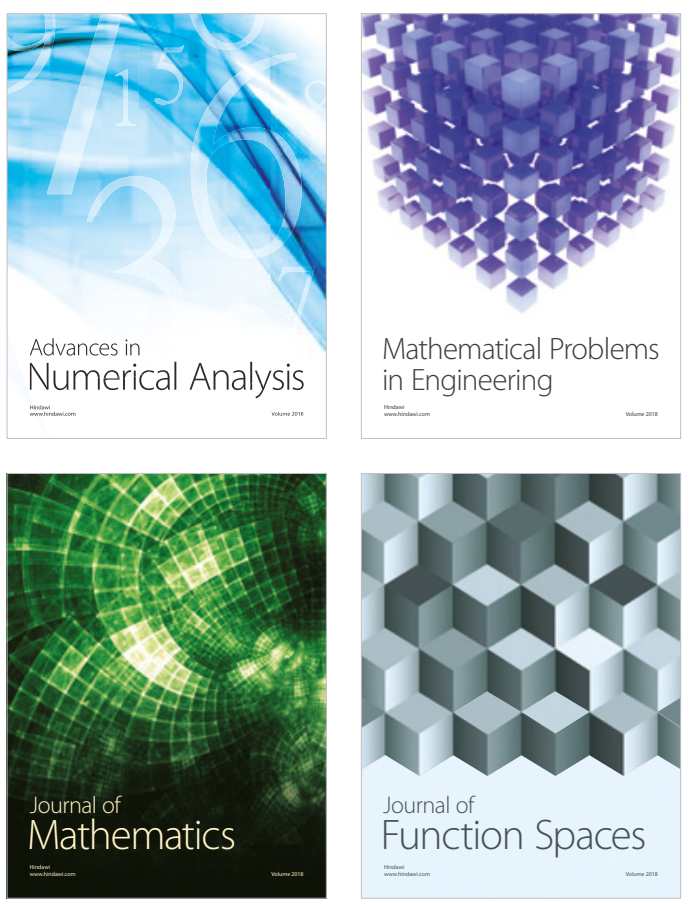

Mathematical Problems in Engineering

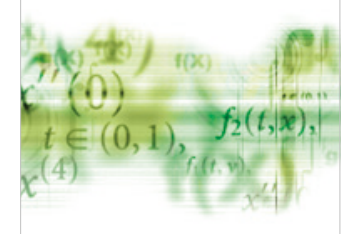

International Journal of

Differential Equations

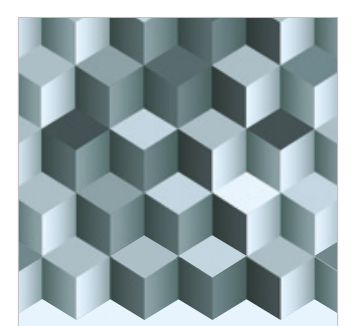

Journal of

Function Spaces

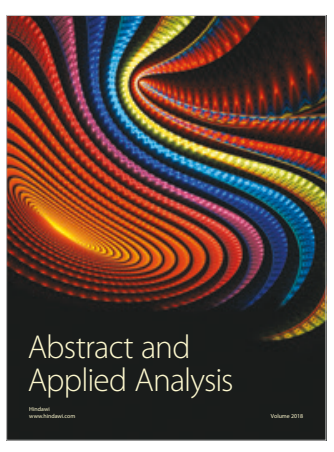

The Scientific

World Journal

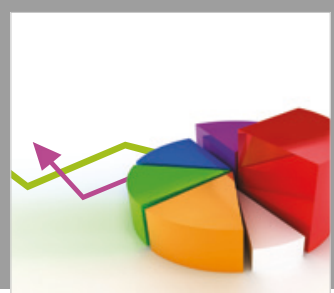

Journal of

Probability and Statistics
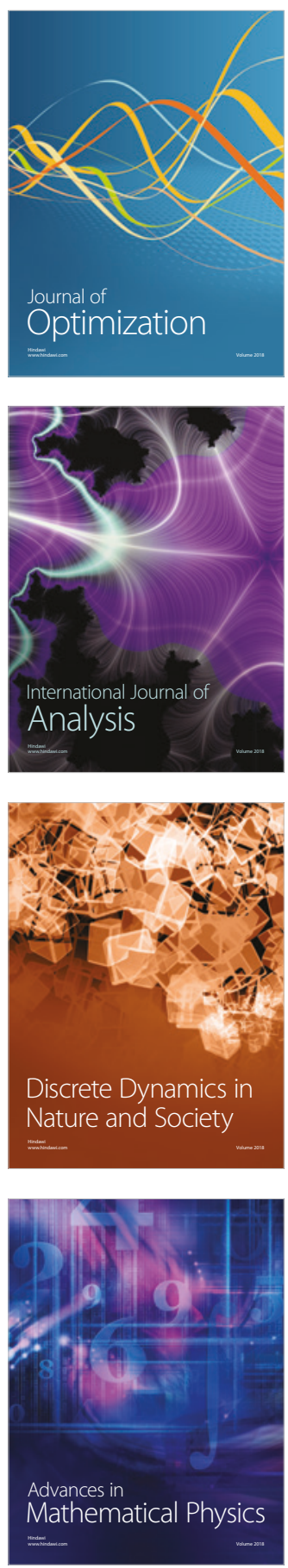